\title{
Experiences with a Hybrid Distance Education Model in Central and Eastern Europe
}

The International Centre for Information Management, Systems, and Services (ICIMSS)

\author{
Czeslaw Jan Grycz \\ The Wladyslaw Poniecki Foundation, Inc.
}

Key words: Distance Education, Central and Eastern Europe, ICIMSS, Poland, Czech Republic, Slovakia, Bulgaria, Hungary, Romania, Information Management, IP, IT, Plagiarism, Peer Review, Torun

\begin{abstract}
The International Centre for Information Management Systems and Services (ICIMSS) is a post-graduate center of education established at Nicholas Copernicus University at Torun, Poland. It serves the continuing education needs of information specialists and librarians from the entire Central and Eastern European region. An international advisory board made up of leading practitioners and academics in the field of information technology designed the curriculum and sees to securing qualified instructors. The faculty utilizes a unique hybrid blend of face-to-face and distance-education technologies to deliver course content. In raising the expectations of a new cadre of librarians to become familiar with accessing and managing electronic resources as well as physical ones, ICCIMS is at the forefront of pushing innovation as well as policy.
\end{abstract}

Allow me briefly to set the context for the ensuing discussion by providing some historical context for the institution (ICIMMS) that is the subject of this paper.

A little more than a decade ago, the Cold War was winding down. The disintegration of the Soviet Union made it possible for Central and Eastern Europe (CEE) once to be again restored to its historical position on the geographic map of Europe. For centuries, CEE nations had acted as a bulwark and had protected Europe against the military and cultural encroachment of Turks, Mongols, Saracens, and Tartars: "infidels from the East." For decades, those same countries had been isolated from the very 
territories they had protected. What Churchill aptly named "the iron curtain" was a symbol, but it was, also a practically impenetrable barrier that stood for over 40 years. When it began to yield, it fell quickly. The unexpectedly rapid collapse of the Soviet system of domination, giving way to more pressing social and economic priorities, allowed the iron curtain countries to be, at last, reunited with their Western European national partners.

It is difficult to exaggerate the importance of this geopolitical shift in control. It has had, in CEE (as beyond), ramifications in all spheres of human activity: commercial, legislative, social, educational, even religious, and, not least, intellectual.

The intellectual perspective of CEE has been an invaluable one throughout history. Positioned as they were, on the main trade and travel routes between the orient and the occident, scholars in CEE historically have been at the heart of the most important problematics in Western thought, contributing greatly to knowledge in philosophy, mathematics, and analytical sciences. The libraries at Krakow, Praha, Sofia, and Budapest were only among the most famous. Libraries in cities like Riga, Bratislava, Zagreb, Eger, and Vilnius held substantial and fascinating collections of their own, especially about local and historical realities.

It was clear that a great and important repository of historically significant data resided in the libraries of CEE universities and municipalities. Wisely, therefore, in the late 1980s the US-headquartered Andrew W. Mellon Foundation began investing significant millions of dollars to modernize and automate selected CEE libraries scattered strategically throughout the region. These funds would not only permit librarians to manage their own collections more efficiently, but also would facilitate the adoption and implementation of international bibliographic standards. Such standards would unlock the specialized collections and repositories that had been sequestered for $40+$ years, and had largely been kept from general scholarly attention.

A not-entirely-hidden intent of the Mellon investment was to revitalize the CEE scholarly and intellectual community itself, helping it re-establish its position among Western and European centers of learning. Libraries have always stood at the pivot of intellectual exchange, academic debate, and the acquisition of knowledge. In the intervening years of the Cold War, the conduct of scholarly publication, its standards, rigorous peer review, and appropriate documentation of sources had all gone through considerable tightening in the West. Moreover, access to Western academic journals and literature was restricted in the iron curtain countries. As a result, scholars from the formerly subjugated regions had some catching up to do, both to conform to the new publication standards, and to become more familiar with the literature that had been published in the West for four decades. Those 
planning the investments in institutional revitalization surely understood the fact that in strengthening libraries, the entire scholarly community could be simultaneously strengthened.

Ironically, the automation grants and the beginnings of attention to educational needs of bibliographic specialists coincided with the insistent reach of the Internet. The Internet penetrated to CEE within hours (or so it seemed) of the fall of the Berlin Wall. It rapidly rode along networks that had been painstakingly established, independently, among universities and institutions of higher education in CEE, and eventually co-opted these and replaced them with high-speed and more reliable linkages. The conduit that reached into CEE (the Internet) worked bisynchronously (in both directions). The Internet itself dramatically altered the conduct of research, challenged (as it has in throughout the world) the centrality of the library for scholarly communication, and opened up entirely new forms of collaboration for CEE scholars. This was a new influence on the practice of academic research. It increased pressure on librarians, exacerbating the difficult process, already underway, of mastering the new automation systems and management approaches that were being introduced along with the (comparatively) simple automation programs.

What became quickly apparent was that an investment in technology and hardware needed to be supplemented by professional education for the practitioners and professionals who would be required to specify needs, install technology, and implement management procedures for maintaining elaborate systems. These new leaders (or existing leaders of libraries with new attitudes to master) needed to develop previously unknown services and deal with new patron demands. Money for instructional purposes was not as available as was money for hardware. This may have been in recognition that true educational impact could only be accomplished within the region by those most familiar with the realities of conditions, structures, and psychology of the managers to be trained. In any case, it was largely up to local initiatives to provide it.

\section{A CENTER FOR EXCELLENCE IN EDUCATION}

ICIMSS is one of the more prominent innovative institutions that emerged to fill the vacuum that was revealed when the need was exposed to provide continual education and professional development opportunities for library managers. Practising librarians who faced multiple challenges, any one of which alone might have been sufficient to suggest a career change to the right-minded, needed training and professional development to deal with real-life problems, e.g.: 
1. unrealistic budgetary constraints,

2. deferred maintenance (that had in some cases become dangerous),

3. collection restoration and development,

4. resource sharing and networking,

5. needed staff training,

6. changing patron demands (and simultaneously providing for their education in new access technologies),

7. gaining adequate Internet experience,

8. mastering new and unfamiliar software,

9. managing complicated computer systems,

10.implementing complex systems with few peers with whom to network, 11. new management challenges and obligations,

12. staff reorganization.

The list can go on.

ICIMSS was situated eventually in Torun, Poland. ${ }^{\text {ii }}$ Torun is a thriving metropolitan area, with a beautiful largely intact Renaissance walled city contained at its heart. It is located some $200 \mathrm{~km}$ northwest of Warszawa. It is the birthplace of Nicholas Copernicus and is his familial home. This explains why Copernicus' name is associated with the University there. But Copernicus' association with ICIMSS is likewise appropriate. The revolution taking place today-the result of improved and ubiquitous telecommunications capabilities-has a sense of Copernican revolution to it. Many feel today's revolution is as transforming of human culture as had been Copernicus' cosmic reorientation.

In the face of the (circumstances/opportunities/challenges) occasioned by these changes, Maria Sliwinska, energetic Deputy Director of the University Library at Nicholas Copernicus University in Torun, began assembling knowledgeable experts to help her address the situation at Torun. The Library at Nicholas Copernicus University had received one of the Mellon grants. Maria was given the responsibility for orchestrating the transition to an automated library system. She felt she needed help in doing it correctly.

She hosted conferences at her university; she invited distinguished guest lecturers to Torun; she sought advice from people who had already gone through the processes that were just beginning in Torun; she interrogated automation and systems vendors for details; she identified world-class leaders in the field of librarianship and informatics on whom she could depend for support; she lobbied her own university for assistance; she participated in early electronic discussion groups; she attended international conferences. She was, in short, indefatigable in gathering to herself the expertise needed to help address the practical implications of integrating high speed network capabilities into a very traditional library environment. 
Ultimately, through the discussions and interactions she had with worldleaders and advisors, it became apparent that a new form of educational facility was needed-nothing less than a new post-graduate Centre of Excellence would satisfy it. The Centre would be a place to which students from the entire region of CEE could come to learn needed skills, be provided with networking possibilities, and be given an opportunity to add to their knowledge in a supportive international context.

\section{PLANNING: GAINING COOPERATION THROUGH AN OPEN PLANNING PROCESS}

Much of ICIMSS' success is due to Maria's dedication and care in appropriately preparing the ground for educational innovation. In hindsight this effort stands out as having been particularly important. In the actual process, it sometimes conveyed a feeling of deliberateness that was not wholly congruent with the energetic spirit of "entrepreneurialism" which otherwise characterized the planning effort that led to the establishment of ICIMSS. International educational activities must be localized and be introduced in a manner consistent with prevailing local culture if they are not to be resisted and unwittingly sabotaged by the very constituencies they are intended to empower.

It was clear that existing library schools in the region (which, at the time, uniformly took a historical approach to librarianship and the book arts) were unprepared to take on the requirements of introducing (much less developing) completely new and innovative curricula. At the same time, those existing schools needed to be willing collaborators in a process that could do so. Not only had they much to benefit from participation, but they also had their own contributions to make through their connection to the networks of professionals, organizations, and libraries in the region.

Similarly, a venture with a specific geographic identity in one country (Poland), if only by virtue of its location, had perforce to include in the planning process representatives from those countries that might provide students to the school. Were this not to happen, libraries in countries from which students were to be sought might feel as if an autocratic hegemony, not well adapted to local needs, was being foisted upon them.

Such considerations appear to be highly psychological and theoretical. Yet, attending to them from the beginning has been effective in generating the overall good will for the Centre and buy-in by all its participants and targeted audiences. 


\section{EXECUTION: DESIGNING CURRICULA AND EXPANDING COMPETENCIES}

Among the most pressing challenges in establishing ICIMSS was designing the curriculum. The curriculum needed to be forward-looking. It also needed to be taught by expert instructors. Engaging the right ones would be essential.

The chosen faculty would need, simultaneously, to (1) deliver instruction; and (2) share pedagogical and methodological insights with local lecturers. (The intent was gradually to replace "imported" instructors with competent local ones).

Having discussed the preliminaries with her advisors, Maria submitted an application for foundation support. Her effort proved successful. A grant was awarded in 1997. from the Open Society Institute's Network Library Program. The grant permitted the formalization of the Centre that had been envisioned by Maria and her "kitchen cabinet." ICIMSS was born.

Knowing how important it was to secure adequate and modern teaching facilities, Maria, had meanwhile convinced University authorities to devote a new central-campus building to ICIMSS, providing it with a modern laboratory of computers, a high-speed fiber-optic network, and unobstructed access to the Internet. This accomplishment, given the times, was an extraordinary and far-sighted expression of confidence by the university administration. They not only recognized the importance of education and research into the practicalities and implications of digital electronic networks for the exchange and management of information, but also acted on their conviction.

In order to jump-start the curriculum design process, syllabi were solicited from leading schools of information technology and management in the US and the UK. These were collated, compared, and modified for the realities of the CEE situation. Eventually, those from the University of Sheffield and Newcastle-Upon-Tyne (in the UK) and the University of Illinois, Urbana-Champaign (in the US) were licensed and used to establish the curriculum at ICIMSS. Participants from CEE libraries and library schools were integral to the curriculum planning and localization process. This guaranteed that what emerged as the ICIMSS curriculum (necessarily modern and innovative) did not deviate too far from local realities that might have reduced its practical impact.

\subsection{English: the Language of Instruction}

One such reality involved language skills. It was decided to employ English as the language of instruction. The reasons advanced in favor of this 
decision were many: The predominant language of the Internet is at present English. The sites and resources of greatest interest to CEE scholars and academics are in English. English is a language that all students from the CEE region would have equal desire to learn. Mastery of English will help students find collaborative opportunities in a United Europe. English descriptive materials makes it possible for likely sponsors and supporters of ICIMSS to learn easily about the goals of the Centre and what it was accomplishing towards achieving those goals. In the field of librarianship (as in so many others), opportunities for networking and problem-solving are greatly expanded if one has a working knowledge of English.

This decision, which on the surface seems self-evident, was not made without appreciating its negative aspects. Among others, it necessarily filtered out a number of potentially interesting and interested student applicants. This awareness led to the evolution of a specific policy about teaching.

\subsection{Training the Trainers through Hands-on Experience.}

For every lecturer brought in from outside the region (largely from the UK or the US), ICIMSS assigns a local co-instructor. Thus there naturally exists a method of "training the trainers." Local instructors actually experience and participate in the methodologies, approaches, and attitudes that can be so different in the West from the more formal educational environment of CEE. It also guarantees that local online resources and indigenous language sites (with which local experts may be familiar) are given equal exposure to the English-language sites and resources with which the visiting instructors are likely to be most comfortable.

The wisdom of assigning a local co-instructor to work with each out-ofthe-region instructor proved particularly effective. Co-instructors often individually help students experiencing difficulty comprehending a lecture delivered in English (especially since these inevitably contain technical jargon). Regional instructors can also, later, localize and repeat the most successful and popular courses in native languages for native-speaking librarians. This rippling effect, expanding the influence of ICIMSS from its centre to specific outlying regions (geographically as well as linguistically), is intentional. It compensates (at least partly) for the perceived disadvantages of conducting lectures exclusively in English. 


\subsection{Adjusting to Working Realities}

Another CEE reality is that library line managers (who generally feel justifiably fortunate in having a safe and stimulating job, and don't want to risk losing one) have insufficient time to leave their institutions for studies lasting a 14-week semester (much less a year or more). Many demands are placed on library institutions in CEE, and too much work needs to be consistently accomplished by prime candidates for studies at ICIMSS for them easily to be away from work for extended periods of time.

The application of distance education technology was an option considered from the start, even though it had not been employed elsewhere in the region at the time. ICIMSS is perhaps the first institution to implement distance education technology in Central and Eastern Europe. But the distance education approach itself needed to be adapted to local conditions. ICIMSS evolved an interesting "hybrid model" that other institutions might be interested in emulating.

Instruction at ICIMSS is based on a standard EU semester of 14-weeks duration. Each semester begins with a two-week session during which the students and instructors meet face-to-face in a conventional lecture/laboratory teaching environment. Students typically enroll in two classes simultaneously. Purposely, ICIMSS' professional development course requirements are designed in a way that exposes the students to one technical class, paired with a class on management theory and practice.

An ICIMSS Advisory Board meeting (or other topically related convention or conference), is generally scheduled to coincide with the opening of the fall semester in Torun. This maximizes the incentive for faculty to travel to Torun. It also provides enrichment possibilities for students who benefit from individual lectures as well as contact with Advisory Board members. This is an example of the frugality that is always a refreshing part of the implementation process in countries used to severely limited budgets. In this instance, the scheduling of the opening of semesters results in close ongoing collaboration between those who plan the curriculum (and provide direction to the course of studies), and those who receive it (and must put it to practice).

The face-to-face exposure has other advantages that are missing in distance education programs that are conducted exclusively online. Professors have long recognized that the bonding of students in a class is an important pedagogical factor. It is very effective when the managerial skills needed to develop teamwork and group problem-solving is as critical to graduating students as it is in information technologies. Team-building skills are particularly useful in today's library environment and are essential in a region in which interaction among various national leadership teams is 
important. By developing a personal relationship with each other (and with their instructors) during a face-to-face opening period, the challenge of submitting assignments "into cyberspace" is made less onerous for students who have not previously been socialized to Internet and web-based e-mail and e-discussions as a predominant form of communication.

Following the initial two-week traditional lecture and laboratory instruction, students return to their homes and work. They fulfil the obligations of their coursework by referring to a web site ${ }^{\text {iii }}$, and by completing assignments and observations utilizing conventional distance education processes via the Internet. Co-instructors (who, too, have returned to their home institutions) continue their instruction from remote locations.

\subsection{Software Support}

There are numerous distance education software packages available for consideration by institutions wishing to employ pre-packaged software to support such an effort as the one at ICIMSS. iParadigms is a company providing an integrated suite of distance education tools that appear particularly attractive. ${ }^{\text {iv }}$ A single installation generates course-specific sets of integrated web pages (along with a master hot-linked index page) that easily provides optional instructor-selected modules, including the following:

1. syllabus,

2. reading list or bibliography,

3. student directory with e-mail addresses,

4. electronic threaded discussion list,

5. course calendar of obligations, assignments, grades and other communications,

6. automated peer review,

7. plagiarism module.

The first four or five may be considered essential for any organization employing distance education models for continuing education, no matter which vendor or software package may be employed. The last two merit additional consideration.

\subsubsection{Automated peer review}

A module that holds exceptional promise is one that makes it possible for assignments to be uploaded to a web site and be automatically redistributed to other students in the class for peer review. Under the implementation trialtested at ICIMSS a student's paper is automatically stripped of its author's identification and is redistributed to two randomly selected classmates. Those classmates are asked to review and critique the assignment, 
submitting an evaluation of it in a brief essay and augmenting the essay by filling in a standardized tabular grading form. As a result of this implementation, each student receives immediate and enriched commentary on each submitted assignment. When added to the instructor's comments, this method provides a good deal more feedback to students than does a normal (instructor commentary only) approach.

In an environment in which the native language of the students is not English, a peer review component additionally reinforces reading and writing comprehension. At the same time as it provides a substantial amount of high quality feedback for the original student, it ipso facto enables the emergence of a shared perception of all the students from the region. They experience a common understanding of the problematics they face and the solutions that can be imagined by each other. The technique reinforces team bonding in the class. It provides the instructor with a higher measure not only of student performance, but also of overall class response to any specific assignment. This last makes it possible for the instructor to gauge continually the effectiveness of the instruction being provided.

\subsubsection{Plagiarism detection}

The use to which the Internet has been put is as creative as the individuals who employ it, which is to say that it is as beneficial or as detrimental as people want to make it. On the detrimental side of the ledger must be listed the emergence of sites pandering to the fears of students. Such sites make available extensive databases of prewritten student assignments and term papers, free for the downloading. ${ }^{v}$

While it is clearly unethical (and intellectually counterproductive) to use such files as replacements for a student's own academic work, many students feel an overwhelming pressure of competitiveness to succeed and are therefore tempted to make use of such resources. They are tempted to believe that prewritten papers may guarantee them a high grade in a class. This is particularly true in the West, where the incidence of cheating is in sharp and alarming increase. The use of the Internet for research is increasing. So is knowledge of the availability of "cheating" sites among students. ${ }^{\mathrm{vi}}$ For many, the temptation is too much to avoid.

The nature of the coursework at ICIMSS is so individualized that recourse to such "Internet paper mill sites" is not at all advantageous. ${ }^{\text {vii }}$ Not all distance education courses, however, can be so customized. The capabilities provided by "plagiarism.org", therefore, may be useful to institutions that depend on more standardized course content.

Detecting plagiarism in student assignments depends on an intelligent Internet "agent" and sophisticated mathematical and analytical algorithms. 
By these means, iParadigms can rapidly compare a student's assignment against its own database of common resources, against printed works (for which electronic checking versions have been licensed by iParadigms) and with URLs that have been identified as sources for student submissions.

An intuitive visual representation of the relationship between the source documents and the student's assignment is provided to the instructor. These analytical reports contain hot-links to any originating documents, making it possible for an instructor easily to see to what extent, or in what form, the student's paper is dependent on the source materials. Then the instructor can either take disciplinary action or (more likely) provide additional instruction on appropriate methods of attribution and citation. ${ }^{\text {viii }}$

\section{RESPONSIVENESS: KEEPING "ON TRACK"}

Providing for continual feedback is an important way to guarantee appropriateness and effectiveness of coursework. It makes it possible for a school such as ICIMSS to retain its relevance and freshness. Students are queried, regularly, both during the courses and immediately after, by means of standardized evaluation forms. Comments and observations made by students are used to modify course content. This allows it to be continually improved and targeted for success.

Distance education provides an example of the more widely observed influence of digital networks - that the emphasis moves from the provider to the receiver. Even in educational settings, the customer (student) is in a position to define satisfaction. This is a significant change from the way education has previously been evaluated. It is part of the "Neo-Copernican" revolution, and useful for students to experience since it so closely echoes their own experience as librarians, for whom patron satisfaction is becoming an increasingly important voice in evaluating library services and even in establishing library budgets.

ICIMSS intends to satisfy students by providing them with the most contemporary, up-to-date, and useful course content that can be delivered. This means that the students have an important role not merely in receiving but in defining the quality of instruction they need.

Clearly, this is a tricky balance to maintain. ICIMSS is attractive because it delivers course content its international advisors have determined to be crucial for the emerging management needs of new libraries. Students cannot be expected to be able to evaluate the verity of the new instructional models. But students can help identify their own priorities of interest within the curriculum, based on the varying value the new content has for the working context in which the students find themselves. So there is an opportunity for 
far more interaction about the curriculum than exists in a more formal and static environment.

Instructors need constantly to establish high academic standards and deliver material with which students may be wholly unfamiliar. The student feedback ensures the applicability of information. It also allows faculty to learn which aspects of library management are of greatest concern to the region.

\section{EVALUATION: WHAT WORKS AND WHAT DOES NOT?}

ICIMSS Professional Development courses run for one and one-half years, and are divided into three semesters. During a full program, students receive 210 hours of instruction. During this time, the students are obliged to master readings, prepare assignments, interact with their peers, and communicate with their instructors.

Since 1977 students have enrolled in the program from various countries of the region, including Austria, Poland, Hungary, Lithuania, Slovakia, and Moldavia.

Given the potential for interactivity, ICIMSS is aware that its graduated students are as valuable to its long-term success as its matriculating students. It is hoped that, as time goes on, the participating ICIMSS community will become larger. ICIMSS hopes that it will be able to retain the interest in its efforts by its graduated classes because these will be increasingly aware of the value of ICIMSS educational approaches, will tend to rely upon ICIMSS for advanced workshops (or, ideally, suggest topics to be covered in specialized courses), and will eventually become employers for students graduating from ICIMSS.

\subsection{Evidence of Success}

An indicator of the success of this approach, even in three short years, is to be found in the fact that ICIMSS graduates have demonstrated improved competencies since completing the program. Reports Maria Sliwinska, "One graduate has established a training centre for librarians in her local region, having successfully applied for and obtained a TEMPUS grant (with the help of lecturers she met at ICIMSS). Another student has become involved with interesting projects and has presented thoughtful papers at a variety of national and even international conferences." Stories of the success of graduates are important indicators, and they have an influence on the future 
of the Centre because their successes reinforce the perception of value in the education they received.

\subsection{Availability of International Expertise}

Despite the advantage of co-instruction (described above), it is clear that one of the distinguishing features of ICIMSS is the exposure it guarantees students to top leaders in library management and instruction from the UK and the US. As library schools throughout the region have themselves begun to address the educational challenges in information management, such differentiation becomes increasingly important to the long-term viability of a Centre such as ICIMSS aspires to be. Systematic access to international experts is unique, and so is the intentional mix of students from countries within the region. These are characteristics that will need to be retained longer perhaps than originally intended. But the mix of imported lecturers and local co-instructors appears to continue to have value. This innovative opportunity to "train the trainer" may also need to be perpetuated.

\subsection{Core Readings}

Among the difficulties that have been observed is the inadequacy of bibliography and reading materials written in native local languages. Consideration has been given to translating core readings into indigenous languages for easier comprehension. For while it is appropriate to expect students to have a core competency in the English language, the concepts and terminology of digital networks is sufficiently new to many students that readings written in the language of the students themselves could be very useful and helpful. But mounting an effort to create translated reading materials is a difficult and expensive proposition. The target of "core works," in addition, is elusive. In the field of information management one could never satisfactorily create a comprehensive database of core literature because it (and supporting software tools) is so rapidly evolving.

One hopes that an increasing amount of literature in native languages will become available for reference in the future. Eventually, some may be written by graduates of ICIMSS. This may lead the ICIMSS Board of Directors to consider providing assistance in the form of establishing a publication outlet or joining forces with a publisher of professional materials. In the meantime, the option of reading the best literature available in the field will continue to depend on English language proficiency. 


\subsection{Marketing}

Marketing efforts are also important to the long-term financial success of courses such as are offered at ICIMSS. In most distance education environments, one can reach an intended audience exclusively through online Internet marketing. In the case of library management, some of the most important targeted students are not regular users of the Internet.

It is, in fact, one of the goals of individual classes to demonstrate the utility of the Internet to access information important to library patrons in CEE. Learning how to navigate the Internet and, more importantly, learning how to filter search results in order to separate quality information from unreliable sources are skills in high demand by librarians. Often it is precisely those who may not be entirely familiar with electronic communication in the first place that can most benefit from such classes. This means, however, that any marketing effort needs to combine more expensive traditional "paper-based" marketing with purely online electronic marketing.

The goal is to reach those librarians and line managers who are leaders, capable of instituting change and likely to benefit most from the courses offered at ICIMSS. Reaching them economically through a successful marketing effort is a challenge likely to continue until the word-of-mouth recommendations of former satisfied students begins to generate its own momentum of referrals and student applications.

\subsection{Financial Support}

One of the biggest challenges faced by ICIMSS and institutions like it in other emerging economies is providing for the travel, accommodation, and training expenses of the students.

ICIMSS finds itself advocating for its students and spending considerable effort generating support to cover student expenses inasmuch as few students can themselves cover the costs involved. The institutions for which they work may be unable or unwilling to cover student costs, or they may be able to contribute only to travel or other portions of a student's expected expenses.

As noted above, it may be expected that as the cadre of satisfied graduates expands, their influence will increase in recommending students and recommending the program to financial decision-makers in their countries. But this will take time. In the meanwhile, the prospects for initiatives like ICIMSS are that they will remain financially vulnerable for some time. Their success will depend greatly on the willingness of volunteer 
efforts to provide the equivalent of "equity" by providing selfless contributions that have the effect of reducing costs in one way or another.

This situation, generally true throughout the world in emerging economic areas, suggests the possibility that international library organizations and consortia can make a profound impact on the future of their colleagues in such emerging economies. Unfortunately, while such initiatives of support could be enormously powerful for the worldwide profession, international outreach is not valued as highly as it needs to be. Truth be told, there are many initiatives that are worthy of assistance, and it is difficult to rise above the many to draw attention to those organizations willing to lend support. Still, awareness of the impact of networking and the disproportionate impact of even modest financial contributions on the delivery of crucial educational resources to worthy students is clear. As professional and national associations of librarians become ever more aware of these realities, it may be that the boards and executive managers may begin to believe in the value of annually allocating a consistent (even small) percentage of their own revenues for the support of their colleagues in less advantaged countries as a matter of policy.

This is a highly optimistic suggestion, but it is hard to imagine any other groups being as aware of and as sensitive to the needs of library education as those who, after all, face precisely the same challenges, but in less financially disadvantaged conditions. Similarly, it is hard to imagine any policy change that could be so important and have so profound an impact on global information transport and utility.

\subsection{Internships}

One practical expression of support can involve no "cash out-of-pocket." Western libraries could invite ICIMSS graduates to participate in internships. This is a major commitment. It necessitates community support for travel costs, accommodation, and living expenses for the period of the internship. Since it is likely that an internship, in order to justify the initial effort and cost, would need to be a minimum of three months (and optimally longer), such costs are not inconsequential. But again the value of personal interaction and exchange is a suitable compensation for the effort.

ICIMSS is ready to work with those willing to provide internships to maximize the effectiveness of any arrangements that are to be made. This may involve selecting the most appropriate student interns to most benefit from an available opening. It will also involve providing clear and systematic evaluation of the experience for all parties. ICIMSS needs to see to it that an intern returns optimal service to the host institution. 
Such arrangements can be very beneficial, especially if the intern and the host institution are carefully paired and the intern is supervised to guarantee a successful apprenticeship for all.

\subsection{Collaborations}

International academic and trade journal publishers, specifically electronic publishers, can benefit in various ways by taking advantage of the fertile environment of creative "out of the box" thinking, that is evidenced by CEE librarians, and, especially, ICIMSS graduates. One of the students, learning about the ability to subscribe to an online document delivery provider and recognizing the value of the service to the researchers at her institution, promptly created an interactive database of digital documents consisting of those that had been requested by individual patrons of her library. Her hypothesis was that, if one researcher found a document interesting, other researchers at her institution would as well. This was a natural and creditable response to her situation. So it was with a certain disappointment that she had to be cautioned that her creative effort might well violate contract law or the licensing agreements imposed by the document provider and owner of proprietary materials. The situation, in the context of an educational experience, provided an opening to discuss critical and challenging issues concerning rights management, intellectual property, and contract law. Such problems involving the homogenizing of international copyright, interest in the behavior of people utilizing electronic documents, and determining the most appropriate mechanisms for digital information delivery are of obvious interest not only to librarians and information managers but to authors, publishers, and research institutions alike.

Publishers can acknowledge several facts about the CEE market. It is an environment that is not likely to be a major growth market for academic journals the next decade or more. It is an environment in which piracy is believed to be taking place. It is one that, as it matures, can be the source, both of new valuable contributions of scholarship as well as new subscriptions. Given these realities, there are several "out of the box" strategies that may be beneficial in both the medium- and the long-term even if the short-term expectations are low. Publishers could, for example, develop new (perhaps national) long-term site licenses (10-20 years in duration) for electronic access to those countries willing to share observations about behavior patterns and statistical usage information in return. ${ }^{\text {ix }}$ Such an outreach effort would be bound to generate interesting data about how people, long kept from utilizing published materials from the West for more than forty years, will initiate programs and implementations to provide their patrons with the benefit of electronic repositories and 
aggregations. It would be interesting to observe what kinds of finding aids, translated metadata resources, indexing, search approaches, and rights management initiatives might emerge. And it would be to the benefit of primary and secondary publishers to encourage the creation of these new forms.

\subsection{Special Targeted Workshops for New Audiences}

An opportunity that exists for ICIMSS, and may for similar educational initiatives elsewhere, is providing targeted workshops in specific information-dependent areas. Some, under consideration at ICIMSS, are workshops on medical informatics, legislative information, art history, environmental public-interest resources, commercial statistical data, etc.

As we move into an increasingly information-dependent millennium (already labelled "The Information Age" by many), such special targets of inquiry provide interesting possibilities. It is also likely that there exist a more economically flexible professional audience for whom specialized information-related courses would be both desired and affordable. These subject areas may be able to generate sufficient revenues to support the educational overheads involved in creating such workshops. In many library and information schools in the West, there is an awareness that graduates with appropriate skills and managerial training in information management may be more valuable to corporate and other commercial entities than they might be to the library community itself.

It is, of course, neither the intent (nor the desire) of ICIMSS to graduate students who would find it more attractive to seek their livelihood outside the library and bibliographic profession. Paradoxically, however, it may prove to be a barometer of overall regional maturity if graduates of ICIMSS are seen to be valuable to the community beyond the libraries and universities currently being served.

\section{IMPLICATIONS}

The results of three years of ICIMSS instruction are encouraging. It is evident that the service and approach provided by ICIMSS to address the professional and development needs of the CEE library community are important. It is clear that the hybrid distance education approach (built on careful planning, implementation, continual feedback, and evaluation) is a model that works in the CEE context (and may be applicable to other international distance education efforts.) 
There exist novel opportunities for primary and secondary publishers to learn about the behavior of researchers and benefit from an unrestricted and "out of the box" creativity by users of electronic documents who already recognize their value in emerging economies. Internship programs and peer networking can provide satisfying international exchange opportunities.

What is most needed is the creative financial support to sustain such vulnerable but important programs as ICIMSS until they can become selfsufficient. In this way, Centres like ICIMSS resemble the very organizations and infrastructure entities that are emerging in the new economies. These and libraries have a symbiotic relationship. It is to the benefit of both, if finances can be found that will help support the students and these new institutions that can provide new ways of thinking in the fertile environments in which they currently exist.

It is also clear that in an Information Age, with global interconnectedness becoming a fact more than merely a vision, benefits exist for the global community of information managers to become involved in providing actual financial and educational support to successful programs in emerging countries, wherever they can be fostered and brought into existence.

${ }^{\mathrm{i}}$ While many of the national libraries suffered the rape of conquerors who carted off incunabula and plundered the collections for rare and precious volumes, others, especially the less prominent, remained more or less intact, if neglected

iiii This decision was not without contention, some advisors feeling that there was a significant advantage to locating the school in a nation's capital city. To date, there seems to have been no negative impact from locating the Centre in another city, and perhaps, in fact, some benefits from fewer distractions, and a greater attention and involvement by its parent institution.

iii The ICIMSS web site, updated more intensively during the period of instruction, is to be found at http://www.poniecki.org/ICIMSS/. Students log on to a proprietary and closed environment which is increasingly supported by iParadigms, Inc., described later in this paper.

iv The iParadigms site is at: http://www.iParadigms.com. By way of official "disclosure," the author wishes to note that he participates in the management and holds a minority share in this company.

${ }^{\mathrm{v}}$ Purveyors of such sites run the risk of prosecution for copyright violation if they charge for the papers contained in their databases, if the papers are not all authored by employees or under "work-for-hire" contracts in the US. Accordingly, most are supported through advertising revenues, while the papers are made available free, "as a service."

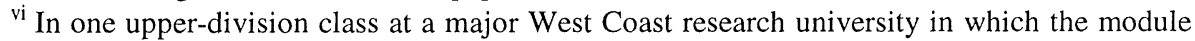
has been implemented for the last three semesters, this dramatic jump is more than evident. A year and a half ago, out of a class of 300 students, one single assignment was identified as having been too heavily dependent on the work submitted to the same course several years earlier by a fraternity brother of a then-enrolled student. During this justconcluded semester, in the same class of approximately the same size, no fewer than 45 students $(15 \%)$ were found to have relied upon resources downloaded from the Internet 
(and many from these "official" cheating sites). Few, of course, provided any attribution; and many exhibited little or no knowledge of how to integrate properly the ideas of others into the intellectual mix of arriving at personal or objective conclusions.

vii The sites that have arisen to provide papers for students often carry wholly ironic and cynical names. Among these are "cheaters.com" and "school_sucks.com" and their ilk, whose names, alone, pander to the negative and lowest instincts of students who feel themselves to be under pressure or whose appreciation of the discipline of education is not wholly formed.

viii A good explanation of the process, along with samples of reports, may be found at http://www.plagiarism.org .

${ }^{i x}$ The idea of a national site license is not entirely novel. Some publishers have discussed the possibility, though none that the author knows has actually implemented such a scheme in CEE. 